\title{
Impact of embryo quality and endometrial thickness on implantation in natural cycle IVF
}

\author{
Vlatka Tomic ${ }^{1} \cdot$ Miro Kasum $^{2} \cdot$ Katarina Vucic ${ }^{3}$
}

Received: 1 October 2019 / Accepted: 12 March 2020 / Published online: 24 March 2020

(c) The Author(s) 2020

\begin{abstract}
Purpose The aim of this study is to assess the effect of the endometrial thickness and embryo quality on the implantation potential in natural cycle IVF (NC-IVF).

Methods A retrospective single-center study was performed on 552 single embryo transfers after NC-IVF. The 'quality' of the embryos was evaluated trough the number and regularity of blastomeres, degree of fragmentation, and nuclear content of cells. Endometrial thickness was measured in millimeters with transvaginal ultrasound on the day of hCG application.

Results Our findings showed a statistically significant difference in successful implantation until a plateau of $10 \mathrm{~mm}$ is reached $(p=0.001)$. Only one pregnancy was achieved where endometrial thickness was less than $7 \mathrm{~mm}$, and this resulted in an early miscarriage. The predictors of favorable implantation were fragmentation $(\leq 10 \%, p<0.05)$ and the number of blastomeres (preferably 8 -cell, $p<0.01)$ on day 3 . Embryo quality $(R=0.052)$ and endometrial thickness $(R=0.18)$ were closely related to pregnancy rate. The overall implantation rate per embryo transfer was $18.8 \%$.

Conclusions Embryo quality and endometrial thickness have a significant impact on implantation in NC-IVF. Highest implantation potential has an 8-cell embryo with $\leq 10 \%$ fragmentation in the third day following oocyte retrieval. Endometrial thickness of at least $7 \mathrm{~mm}$ seems to be the optimal edge of successful pregnancy.
\end{abstract}

Keywords Embryo $\cdot$ Endometrial thickness $\cdot$ Pregnancy rate $\cdot$ Natural cycle IVF $\cdot$ Prognostic factors

\section{Introduction}

Natural cycle IVF (NC-IVF) is a safe, low-cost, and patient friendly alternative to conventional controlled ovarian stimulation (COS). Those patients that could benefit from NC-IVF include those with a poor ovarian response, with a history of previous ovarian hyperstimulation syndrome (OHSS), and subfertile couples $[1,2]$. Furthermore, without hormonal stimulation drug-induced side effects could be avoided. Patients who would prefer to have a more natural approach

Vlatka Tomic

tomic.vlatka@gmail.com

1 Department of Obstetrics and Gynecology, Paracelsus Medical University, Müllner Hauptstrasse 48, 5020 Salzburg, Austria

2 Department of Obstetrics and Gynecology, School of Medicine, University Hospital Centre Zagreb, University of Zagreb, Zagreb, Croatia

3 European Medicines Agency, Amsterdam, The Netherlands for personal, ethical, and religious reasons may also find natural IVF a suitable solution.

Endometrial receptivity and embryo quality are important factors of successful outcomes in stimulated IVF cycles [3].

Endometrial receptivity is a result of effects provided by ovarian steroid hormones, and is synchronized with fertilization and embryo development [4]. Extremely deviant endometrial morphology on the day of oocyte retrieval in stimulated IVF cycles with embryo transfer (ET) has been associated with deleterious effects on clinical pregnancy [5]. Measurement of the endometrial thickness by ultrasound is a simple, non-invasive method that has been studied as an indicator of endometrial receptivity, and a possible predictor of the potential success of IVF-ET treatment.

Findings are, however, inconclusive due to different induction protocols in use, limited sample sizes and various inclusion criteria [6-9]. Embryo quality is primarily assessed through an embryo grading system where embryos are graded according to their morphological appearance and are given a score that relates to their development at the time 
of assessment [10]. The goal is to provide a more precise estimate of implantation potential [11].

In contrast to a stimulated IVF cycle, in NC-IVF the treatment target is one follicle that spontaneously develops to dominance, which results in most of the cases with availability of single embryo for transfer. Conventional IVF-ET and three NC-IVF treatments lead to a similar cumulative pregnancy rate, but the cost per pregnancy is $15 \%$ lower in NC-IVF $[12,13]$. In addition, the embryo quality seems more favorable in NC-IVF when compared with conventional IVF [14]. A study from 2018 by von Wolff et al. [15] found thin endometrium as an independent negative prognostic factor in NC-IVF.

NC-IVF provides a unique opportunity to study and relate embryo characteristics to their implantation potential, without any selection or biases. The aim of our study is to assess the effect of endometrial thickness and embryo quality on the implantation potential in NC-IVF.

\section{Patients and methods}

The study included 552 cases of ET after NC-IVF performed between 2010 and 2017 at University Hospital Center Sisters of Mercy, Zagreb, Croatia. Our study was exempt from the Institutional Review Board approval since it was a retrospective review of data already collected anonymously.

Inclusion criteria were as follows: patients aged $<38$ years, $\mathrm{BMI} \leq 25 \mathrm{~m}^{2} / \mathrm{kg}$ and one available embryo for transfer in a non-stimulated cycle where only human chorionic gonadotropin (hCG; Ovitrelle, Serono, Geneva, Switzerland) for triggering ovulation was used. No drugs were administered to prevent premature luteinizing hormone (LH) surge and possible rupture of the follicules. Serum concentrations of estradiol, progesterone, follicle stimulating hormone (FSH), and $\mathrm{LH}$ in serum were measured at the start of monitoring (first to fourth day of the cycle). On subsequent regular control visits estradiol, progesterone and LH were measured every 2 days, followed by ultrasound measurement of the follicle and endometrium thickness in millimeters $(\mathrm{mm})$. By ascending slope of $\mathrm{LH}(>20 \mathrm{mIU} / \mathrm{mL})$ with decreasing estradiol levels and progesterone $\geq 1.5 \mathrm{ng} /$ $\mathrm{mL}$, the NC-IVF cycle was cancelled. Although monitoring for NC-IVF in our center is intensive, the cancellation rate was $12.4 \%$. When the leading follicle was sized $18-20 \mathrm{~mm}$, hCG was applied and the aspiration was performed $36 \mathrm{~h}$ later with the oocyte inseminated with motile spermatozoa approximately $2-5 \mathrm{~h}$ later. Fertilization was assessed $20 \mathrm{~h}$ later by determination of the number of pronuclei. The total rate of NC-IVF cycles with retrieved oocytes was $77.2 \%$, and the fertilization rate was $82.4 \%$ with embryos scored 48 and $72 \mathrm{~h}$ after insemination.

The 'quality' of the embryos was evaluated through the number and regularity of blastomeres, degree of fragmentation, and nuclear content of cells. Embryos with more than two pronuclei and fragmentation of $\geq 50 \%$ were discarded for transfer.

Embryo transfer was performed $72 \mathrm{~h}$ after oocyte retrieval using a Cook soft catheter (K-soft 5100, Cook, Brisbane, Australia).

Measurement of the greatest endometrial thickness in the longitudinal plane of the uterus in transvaginal ultrasound (Voluson S6 and Voluson S8, RIC 5-9W, GE Healthcare) was measured from one endometrial-myometrium interphase to the corresponding interphase. The measurement recorded on the day of hCG administration was used as the referral value in this study. Pregnancy was first assessed by a positive hCG test 2 weeks after the oocyte retrieval and was confirmed by ultrasound visualization of intrauterine gestational sac with an embryo with heartbeats at 6 weeks gestational age.

\section{Statistical analysis}

Statistical analysis was performed with SPSS 18.0. software (SPSS, Inc., Chicago, IL). A $\chi^{2}$ test was used to compare differences in patient and cycle characteristics and endometrial thickness on the day of hCG administration between pregnant and non-pregnant women. Logistic regression analysis was applied to determinate the influence of specific embryo characteristics on implantation. After univariate analysis, factors with $p<0.25$ were retained for multivariate analysis. Multiple logistical regression analysis was used to assess the impact of endometrial thickness and embryo quality on outcome of NC-IVF. $p<0.05$ was considered statistically significant.

\section{Results}

The patients are divided into two groups, pregnant or nonpregnant women based on the $\beta$-hCG pregnancy test 2 weeks after ET and confirmed by transvaginal ultrasound examination at 6 weeks of gestation if the gestational sac with an embryo with heartbeats was present.

Patient and cycle characteristics are presented in Table 1. Age, body mass index (BMI), number of oocyte retrieved, number of embryos transferred, and estradiol serum level at hCG trigger showed comparable results between two groups. Embryo quality and endometrial thickness $(11.4 \mathrm{~mm} \pm 2.7 \mathrm{~mm}$ vs. $8.6 \mathrm{~mm} \pm 2.3 \mathrm{~mm})$ were higher in pregnant women than in non-pregnant $(p<0.05)$.

Pregnancy rate and endometrial thickness on day of hCG administration are shown in Table 2. Only one pregnancy was achieved with endometrium thickness less than $7 \mathrm{~mm}$ and this resulted in early miscarriage (Table 2). The nine miscarriages were registered in the group of pregnant 
Table 1 Patient and cycle characteristics

\begin{tabular}{lrrl}
\hline & $\begin{array}{l}\text { Pregnant } \\
\text { women, } \\
N=104\end{array}$ & $\begin{array}{l}\text { Non-preg- } \\
\text { nant women, } \\
N=448\end{array}$ & $p$ value \\
\hline Age (years) & $33.2 \pm 3.8$ & $34.1 \pm 3.3$ & NS \\
BMI (m $/ \mathrm{kg})$ & $24.4 \pm 2.6$ & $24.1 \pm 3.4$ & $\mathrm{NS}$ \\
Endometrial thickness (mm) & $11.4 \pm 2.7$ & $8.6 \pm 2.3$ & $<0.05$ \\
Number of oocytes retrieved & $1.1 \pm 0.2$ & $1.1 \pm 0.1$ & $\mathrm{NS}$ \\
Number of embryos trans- & $1.1 \pm 0.1$ & $1.0 \pm 0.1$ & $\mathrm{NS}$ \\
$\quad$ ferred & $0.4 \pm 0.1$ & $0.3 \pm 0.2$ & $<0.05$ \\
$\begin{array}{l}\text { Top quality embryos } \\
\text { Estradiol at hCG trigger }(\mathrm{pg} /\end{array}$ & $268 \pm 52$ & $246 \pm 74$ & $\mathrm{NS}$ \\
$\quad \mathrm{mL})$ & & & \\
\hline
\end{tabular}

$N S=$ non-significant

Table 2 Pregnancy rate and endometrial thickness on day of hCG application

\begin{tabular}{llll}
\hline $\begin{array}{l}\text { Endometrial } \\
\text { thickness }\end{array}$ & Pregnant women & Non-pregnant women & $p$ value \\
\hline$\leq 6 \mathrm{~mm}$ & 1 & 71 & $<0.0001$ \\
$7 \mathrm{~mm}$ & 4 & 64 & $<0.0001$ \\
$8 \mathrm{~mm}$ & 6 & 124 & $<0.0001$ \\
$9 \mathrm{~mm}$ & 11 & 70 & $<0.0001$ \\
$10 \mathrm{~mm}$ & 15 & 39 & 0.0011 \\
$11 \mathrm{~mm}$ & 16 & 21 & $\mathrm{NS}$ \\
$12 \mathrm{~mm}$ & 20 & 24 & $\mathrm{NS}$ \\
$13 \mathrm{~mm}$ & 14 & 13 & $\mathrm{NS}$ \\
$14 \mathrm{~mm}$ & 11 & 12 & $\mathrm{NS}$ \\
$15 \mathrm{~mm}$ & 3 & 6 & $\mathrm{NS}$ \\
$16 \mathrm{~mm}$ & 2 & 3 & $\mathrm{NS}$ \\
$\geq 17 \mathrm{~mm}$ & 1 & 1 & $\mathrm{NS}$ \\
Total 552 & $104(18.8 \%)$ & $448(81.2 \%)$ & \\
\hline
\end{tabular}

$N S=$ non-significant

women with endometrial thickness of $\geq 7 \mathrm{~mm}$. Overall miscarriage rate was $9.6 \%$. Our results indicate a statistically significant difference in successful implantation until a plateau of $10 \mathrm{~mm}$ is reached $(p=0.0011)$. After cutoff value of $10 \mathrm{~mm}$, the difference in endometrial thickness between pregnant and nonpregnant women was not statistically significant.

The implantation rate was $18.8 \%$ (104/552) per embryo transfer and clinical pregnancy rate was $17.03 \%$ (94/552). The birth rate was not analyzed in this study. According to the embryo quality, the highest implantation rate was found with 8 -cell embryos on day 3 , having $\leq 10 \%$ fragmentation, symmetrical blastomeres, and an absence of multinucleated blastomeres, i.e. so-called "top quality embryos". In univariate and multivariate analyses, embryos with fragmentation less or equal to $10 \%$ showed the highest implantation
Table 3 Impact of embryo quality on implantation rate-regression analysis

\begin{tabular}{|c|c|c|c|c|}
\hline & \multicolumn{2}{|c|}{$\begin{array}{l}\text { Univariate } \\
\text { analysis }\end{array}$} & \multicolumn{2}{|c|}{$\begin{array}{l}\text { Multivariate } \\
\text { analysis }\end{array}$} \\
\hline & ${ }^{\mathrm{a}} \mathrm{OR}$ & $p$ value & OR adj & $p$ value \\
\hline \multicolumn{5}{|l|}{ Embryo characteristics } \\
\hline $\begin{array}{l}\text { Blastomeres number day } 2 \text { ( } \geq 3 \\
\text { vs. 2) }\end{array}$ & 1.70 & ${ }^{\mathrm{a}} \mathrm{NS}$ & 1.62 & NS \\
\hline $\begin{array}{l}\text { Blastomeres number day } 3 \text { (8 vs. } \\
3-7 \text { ) }\end{array}$ & 2.48 & $<0.01$ & 2.18 & $<0.01$ \\
\hline $\begin{array}{l}\text { Fragmentation day } 3(\leq 10 \% \\
\text { vs. }>10 \%)\end{array}$ & 1.93 & $<0.01$ & 1.71 & $<0.05$ \\
\hline $\begin{array}{l}\text { Fragmentation day } 3(\leq 20 \% \\
\text { vs. }>20 \%)\end{array}$ & 1.78 & $<0.05$ & 1.68 & $<0.05$ \\
\hline $\begin{array}{l}\text { Multinuclear present (never vs. } \\
\text { ever) }\end{array}$ & 1.54 & NS & 1.46 & NS \\
\hline $\begin{array}{l}\text { Blastomeres shape (symmetrical } \\
\text { vs. non-symmetrical) }\end{array}$ & 1.61 & NS & 1.48 & NS \\
\hline
\end{tabular}

${ }^{\text {a } N S}$ non-significant, $O R$ odds ratio

Table 4 The relationship between endometrial thickness and embryo quality on IVF outcome-multiple logistical regression analysis

\begin{tabular}{lcc}
\hline Independent variable & Endometrial thickness & $\begin{array}{l}\text { Embryo } \\
\text { quality } \\
\text { (top) }\end{array}$ \\
\hline Regression coefficient & 0.18 & $\begin{array}{c}0.052 \\
<0.01\end{array}$ \\
$p$ value & $<0.05$ & $<0.05$ \\
\hline
\end{tabular}

potential and in utero survival $(p<0.01$ and $p<0.05$, respectively). Day 3 fragmentation of $\leq 20 \%$ also presented as a marker of implantation success in NC-IVF versus embryos with $>20 \%$ fragmentation (Table 3 ).

Blastomere numbers on day 3, but not on the day 2, showed predictive values $(p<0.01)$ for ongoing pregnancy. The overall implantation rate per embryo transfer was $18.8 \%$.

Influence of endometrial thickness and embryo quality on implantation potential suggests their independent effects on pregnancy rate when analyzed by multiple regression analysis (Table 4).

\section{Discussion}

The embryo characteristics identified as the most optimal ( 8 cells on day 3 with less or equal to $10 \%$ of fragmentation) corresponded, as expected, with highest pregnancy rate in NC-IVF in this study.

The administration of gonadotropins in stimulated IVF cycles may influence the cleavage capacity of embryos, although Ziebe et al. [16] found comparable embryo quality and cleavage stages between natural and stimulated cycles. 
The receptivity of the endometrium may be adversely affected by ovarian hyperstimulation, leading to a discordant maturation between the embryo and the endometrium which may result in failed implantation [17]. In vitro studies have revealed novel roles for the decidualized endometrium as a biosensor of embryo quality, with the embryo itself responsible for $\sim 30 \%$ of implantation failures, whereas inadequate uterine receptivity is responsible for approximately $70 \%$ of implantation failures [18]. Furthermore, higher endometrial thickness observed in stimulated cycles may be related with more mature endometrium that favors embryos with higher number of blastomeres, i.e. in more advanced stage of development.

Endometrial characteristics in natural cycle IVF are considerably different from those in medically induced cycles [19]. In NC-IVF two cells embryos in day 2 without any other abnormalities were found to have good implantation potential.

Multivariate analysis showed that blastomere numbers of at least two did not influence their implantation potential. Pelinck et al. [20] suggested that the implantation potential of embryos with a low number of blastomeres on day 2 is underestimated, which was confirmed by findings of our study. Blastomere numbers on day 3 had a strong predictive value of their implantation potential, underpinning 8-cell as a significant factor in clinically successful pregnancy. Fragmentation is the other significant factor. An almost twofold increase in ongoing pregnancy rates were observed for fragmentation up to $10 \%$ in our results. Even fragmentation of $\leq 20 \%$ presented with similar OR when compared with fragmentation $>20 \%$. When compared with NC follicles, putative markers associated with oocyte quality and follicle maturation were significantly different from those in gonadotropin-stimulated follicles [21]. Therefore, it is unclear whether the results of our study apply to embryos derived from COS, although similar findings are observed in the previous COS-IVF studies [22, 23]. One study revealed a significant negative impact of multinucleation on implantation and birth in COS-IVF [24], whereas our study failed to demonstrate such a relationship in NC-IVF.

In our study, endometrial thickness of at least $7 \mathrm{~mm}$ is found to be the optimal margin for successful implantation in NC-IVF. Conflicting results exist concerning the possible relationship between endometrial thickness and treatment outcome after IVF [3, 6-8, 25]. The majority of previous studies reported small series (less than 200 cycles) or used different ovarian stimulation protocols. Systematic review and meta-analysis, although limited with heterogenity of study data, showed that pregnancy rates improved with increasing endometrial thickness, but pregnancy rates still appeared to be significantly lower up to an endometrial thickness value of $\leq 10 \mathrm{~mm}$ [26]. The authors do not recommend the use of endometrial thickness as a tool to decide on cycle cancellation. The differences that induction protocols and/or multiple embryos may bring are overcome in NCIVF, which may serve as the best model for investigating the possible link between embryo quality, endometrial thickness, and implantation success.

The endometrial thickness threshold established in our finding is $7 \mathrm{~mm}$, below which pregnancy rate decreased rapidly. More than $50 \%$ of pregnancies with endometrial thickness below $7 \mathrm{~mm}$ resulted in spontaneous miscarriage [8, 16, 27]. A study of Al-Ghamdi et al. [28] demonstrated a significant increase in the pregnancy rate with increasing endometrial thickness, even independent of the quality of embryos transferred. Their conclusion was confirmed in a recent study of Liu et al. [29]. However, direct comparison between NC-IVF and conventional IVF is hard, since hormonal milieu and treatment form differ significantly. The only NC-IVF study by von Wolff et al. [15] showed reduced pregnancy rate with an endometrial thickness $\leq 7 \mathrm{~mm}$, but in contrast to conventional IVF a tendency to lower pregnancy rate with thick endometria $(>11 \mathrm{~mm})$. In contrast, in our study after cut-off value of $10 \mathrm{~mm}$, the difference in endometrial thickness between pregnant and non-pregnant women was not statistically significant.

In our study, lower endometrial thickness (but not lower than $7 \mathrm{~mm}$ ) and high embryo quality were predictors of successful pregnancy and vice versa. It seems reasonable to believe that to some extent higher endometrial thickness could compensate the poorer embryo quality and vice-versa, but with embryo quality below optimum $(\leq 20 \%$ fragmentation, $6-8$ cells on day 3 ) and endometrial thickness below $7 \mathrm{~mm}$ the chance of successful pregnancy is poor.

Our study is, to our best knowledge, the first large homogenous cohort of NC-IVF investigating and connecting embryo quality and endometrial thickness. Nevertheless, some limitations have to be discussed, such as retrospective design and therefore chance of biases as well as results limited to women below 38 years of age and natural cycle IVF.

\section{Conclusion}

Embryo quality and endometrial thickness have significant impact on implantation in NC-IVF. Highest implantation potential has 8 -cell embryos with less or equal to $10 \%$ fragmentation on third day following oocyte retrieval. Endometrial thickness of at least $7 \mathrm{~mm}$ seems to be the optimal edge of successful pregnancy.

Acknowledgements Open access funding provided by Paracelsus Medical University. 
Author contribution VT: project development, data collection, manuscript writing, data analysis. MK: manuscript editing, data management. KV: manuscript writing, data analysis.

\section{Compliance with ethical standards}

Conflict of interest The authors declare that they have no conflicts of interest.

Ethical approval All procedures performed in studies involving human participants were in accordance with the ethical standards of the institutional and/or national research committees and with the 1964 Helsinki Declaration and its later amendments or comparable ethical standards.

Informed consent For this type of study, formal consent was not required.

Open Access This article is licensed under a Creative Commons Attribution 4.0 International License, which permits use, sharing, adaptation, distribution and reproduction in any medium or format, as long as you give appropriate credit to the original author(s) and the source, provide a link to the Creative Commons licence, and indicate if changes were made. The images or other third party material in this article are included in the article's Creative Commons licence, unless indicated otherwise in a credit line to the material. If material is not included in the article's Creative Commons licence and your intended use is not permitted by statutory regulation or exceeds the permitted use, you will need to obtain permission directly from the copyright holder. To view a copy of this licence, visit http://creativecommons.org/licenses/by/4.0/.

\section{References}

1. Ubaldi F, Rienzi L, Ferrero S, Baroni E, Iacobelli M, Sapienza F, Minasi MG, Cobellis L, Romano S, Scarselli F, Greco E (2004) Natural in vitro fertilization cycles. Ann NY Acad Sci 1034:245-251

2. Schimberni M, Morgia F, Colabianchi J, Giallonardo A, Piscitelli C, Giannini P, Montigiani M, Sbracia M (2009) Natural-cycle in vitro fertilization in poor responder patients: a survey of 500 consecutive cycles. Fertil Steril 92:297-301

3. Zhao J, Zhang Q, Wang Y, Li Y (2014) Endometrial pattern, thickness and growth in predicting pregnancy outcome following 3319 IVF cycle. Reprod Biomed Online 29:291-298

4. von Wolff M (2019) The role of natural cycle IVF in assisted reproduction. Best Pract Res Clin Endocrinol Metab 33:35-45

5. Bourgain C, Devroey P (2007) Hystological and functional aspects of the endometrium in the implantation phase. Gynecol Obstet Invest 64:131-133

6. Bu Z, Sun Y (2015) The impact of endometrial thickness on the day of human chorionic gonadotrophin (hCG) administration on ongoing pregnancy rate in patients with different ovarian response. PLoS ONE 30(10):e0145703

7. Traub ML, Van Arsdale A, Pal L, Jindal L, Santoro N (2009) Endometrial thickness, caucasian ethnicity, and age predict clinical pregnancy following fresh blastocyst embryo transfer: a retrospective cohort. Reprod Biol Endocrinol 7:33

8. Okohue JE, Onuh SO, Ebeigbe P, Shaibu I, Wada I, Ikimalo JI, Okpere EE (2009) The effect of endometrial thickness on in vitro fertilization (IVF)-embryo transfer/intracytoplasmic sperm injection (ICSI) outcome. Afr J Reprod Health 13:113-121

9. El-Toukhy T, Coomarasamy A, Khairy M, Sunkara K, Seed P, Khalaf Y, Braude P (2008) The relationship between endometrial thickness and outcome of medicated frozen embryo replacement cycle. Fertil Steril 89:832-839
10. Yu CH, Zhang RP, Li J, ZC A (2018) A predictive model for highquality blastocyst based on blastomere number, fragmentation, and symmetry. J Assist Reprod Genet 35:809-816

11. Tiitinen A (2019) (2019) Single embryo transfer: why and how to identify the embryo with the best developmental potential. Best Pract Res Clin Endocrinol Metab 33:77-88

12. Haemmerli Keller K, Alder G, Loewer L, Faeh M, Rohner S, von Wolff M (2018) Treatment-related psychological stress in different in vitro fertilization therapies with and without gonadotropin stimulation. Acta Obstet Gynecol Scand 97:269-276

13. von Wolff M, Rohner S, Santi A, Stute P, Popovici R, Weiss B (2014) Modified natural cycle in vitro fertilization an alternative in vitro fertilization treatment with lower costs per achieved pregnancy but longer treatment time. J Reprod Med 59:553-559

14. Kollmann Z, Schneider S, Fux M, Bersinger NA, von Wolff M (2017) Gonadotrophin stimulation in IVF alters the immune cell profile in follicular fluid and the cytokine concentrations in follicular fluid and serum. Hum Reprod 32:820-831

15. von Wolff M, Fäh M, Roumet M, Mitter V, Stute P, Griesinger G, Kohl Schwartz A (2018) Thin endometrium is also associated with lower clinical pregnancy rate in unstimulated menstrual cycles: a study based on natural cycle IVF. Front Endocrinol (Lausanne) 20(9):776

16. Ziebe S, Bangsbøll S, Schmidt KL, Loft A, Lindhard A, Nyboe Andersen A (2004) Embryo quality in natural versus stimulated IVF cycles. Hum Reprod 19:1457-1460

17. Fatemi HM, Popovic-Todorovic B (2013) Implantation in assisted reproduction: a look at endometrial receptivity. Reprod Biomed Online 27:530-538

18. Koot YE, Macklon NS (2013) Embryo implantation: biology, evaluation, and enhancement. Curr Opin Obstet Gynecol 25:274-279

19. Haritha S, Rajagopalan G (2003) Follicular growth, endometrial thickness and serum estradiol levels in spontaneous and clomiphene citrate-induced cycles. Int J Gynecol Obstet 81:287-292

20. Pelinck MJ, Hoek A, Simons AHM, Heineman MJ, Van EchtenArend J, Arts EG (2010) Embryo quality and impact of specific embryo characteristics on ongoing implantation in unselected embryos derived from modified natural cycle in vitro fertilization. Fertil Steril 94:527-534

21. Lu CL, Yan ZQ, Song XL, Xu YY, Zheng XY, Li R, Liu P, Feng HL, Qiao J (2019) Effect of exogenous gonadotropin on the transcriptome of human granulosa cells and follicular fluid hormone profiles. Reprod Biol Endocrinol 24(17):49

22. Holte J, Berglund L, Milton K, Garello C, Gennarelli G, Revelli A, Bergh T (2007) Construction of an evidence-based integrated morphology cleavage embryo score for implantation potential of embryos scored and transferred on day 2 after oocyte retrieval. Hum Reprod 22:548-557

23. Van Royen E, Mangelschots K, De Neubourg D, Laureys I, Ryckaert G, Gerris J (2001) Calculating the implantation potential of day 3 embryos in women younger than 38 years of age: a new model. Hum Reprod 16:326-332

24. Fauque P, Audureau E, Leandri R, Delaroche L, Assouline S, Epelboin S, Jouannet P, Patrat C (2013) Is the nuclear status of an embryo an independent factor to predict its ability to develop to term? Fertil Steril 99:1299-1304

25. Rashidi BH, Sadeghi M, Jafarabadi M, Tehrani Nejad ES (2005) Changes in measured endometrial thickness predict in vitro fertilization success. Eur J Obstet Gynecol Reprod Biol 120:179-184

26. Kasius A, Smit JG, Torrance HL, Eijkemans MJ, Mol BW, Opmeer BC, Broekmans FJ (2014) Endometrial thickness and pregnancy rates after IVF: a systematic review and meta-analysis. Hum Reprod Update 20:530-541

27. Richter KS, Bugge KR, Bromer JG, Levy MJ (2007) Relationship between endometrial thickness and embryo implantation, based on 
1294 cycles of in vitro fertilization with transfer of two-blastocyststage embryos. Fertil Steril 87:53-59

28. Al-Ghamdi A, Coskun S, Al-Hassan S, Al-Rejjal R, Awartani K (2008) The correlation between endometrial thickness and outcome of in vitro fertilization and embryo-transfer (IVF-ET) outcome. Reprod Biol Endocrinol 6:37

29. Liu KE, Hartman M, Hartman A, Luo ZC, Mahutte N (2018) The impact of a thin endometrial lining on fresh and frozen-thaw IVF outcomes: an analysis of over 40,000 embryo transfers. Hum Reprod 33:1883-1888

Publisher's Note Springer Nature remains neutral with regard to jurisdictional claims in published maps and institutional affiliations. 